\title{
Development and Research of Video Teaching Resource in Fine Course Construction
}

\author{
Xu Ruiying \\ Baicheng Normal College, Media Institute \\ Baicheng ,Jilin \\ Xuruiying1979@yahoo.com.cn
}

\begin{abstract}
Video teaching resource in fine course construction is an important part in fine course construction. Making every aspect of teaching video resource well is the important guarantee for providing high-quality video teaching resource.
\end{abstract}

Keywords-Fine course; video teaching; staff; technology; manuscript

\section{INTRODUCTION}

The aim of constructing fine course is to improve education quality by providing high-quality teaching resource. As teaching video resource works as video teaching resource of fine course, it is the core part to reflect the value of fine course. Thus education, science, technology and art are integrated into this, especially the education. If we want to develop high-quality video teaching resource, we must combine education with technology, that is, perfect combination of teacher's teaching and making video technology, in which designing is the most important. If we want to achieve the educational value in teaching video, we should strictly obey the rules in making it.

\section{STAFF'S COMMUNICATION:}

The communication with teacher is important before the fine course. On one hand, the technician can better choose pictures by knowing the style and feature of the teacher's teaching and the whole flow of the class; on the other hand, teacher can prepare it in psychology, and he would pay attention to dress, speech, blackboard-writing to comply with the video needs, interact with students and use appropriately multimedia courseware. The teacher can use introduction, inspiration, questions, discussion and other forms to motivate students' learning interest so that the video quality could be better and the best teaching effect can be achieved. When the teacher interacts with the students, the shot change and voice collecting are crucial. So if they communicate with each other well, they will know what they should concern so clearly that the teaching process would be smoother, which is good for shooting and later editing.

\section{TECHNOLOGY PREPARATION}

We usually use two sets of cameras. One is for teacher and the other is for students. Voice collecting is very crucial. If there is any noise in the video, it influences the video quality. Because collecting teacher's voice is more important, teacher should wear the color with a microphone and students' voice is collected by SONY capacitor. The two kinds of voices are both connected with BETA CAM channel by audio cable which can make sure the high-quality of recording present voice. In addition, adjusting the machines before the video can make sure the normal operation.

Choosing aperture: The platform of the multimedia classroom is low-light, because the contents on projection screen should be clear; while the students' place is high-light by increasing fluorescent lamps' illumination. To keep a real teaching environment as usual, we can adopt the shooting method of combining automatic aperture with manual aperture. When teaching activity and contents on screen are close shot, we adopt manual aperture to increase aperture and exposure while it change to full shot, we adopt automatic aperture.

Determine the time of shot: there is no strict rule on the length of the shot in fine course video, but the monotonous and long shot is boring and continuous short shot loses reality. Therefore we use full or close shot more and close-up shot less; the shot with special focus is long and monotonous shot is short.

Shot type: Shot is usually grouped into full shot, mid-shot, close shot and close-up shot. Full shot is used in the beginning and ending of fine course video to introduce and show the full teaching view such as classroom environment, students' activity and teacher's manner. And it can emphasize atmosphere and scene of class; Mid- shot is mainly used in the middle of fine course video to reveal the emotion, identity and move of the subjects such as teaching, blackboard-writing and interactions between teacher and students. There is not only subject but also surrounding environment related to subject. For example, if the teacher is the subject, the surrounding environment such as blackboard, platform and screen plays as foil.

In the middle the mid-shot and close shot is mainly used for teaching activity, blackboard-writing, operation and teacher. If mid-shot is used when a student is answering a question, the emotion and manner of the student is shoot; close shot is used to show individual psychological activity and facial expression which gives you a feeling of communication, for example, teaching, blackboard-writing, answering questions and so on. Close-up shot is the amplification of subject or small part in full screen. It emphasizes the subject from surrounding environment which gives you special visual perception. So people will be impressed with the special scene such as facial expression and manner of teacher and students, contents of blackboard, contents on screen and so on. 
Application of shot: During the fine course teaching video, we usually adopt zoom by pushing, pulling, waving and following. Pushing: the scene is changed from large-scale view to small-scale view gradually in the shooting. A subject or visual part emerges suddenly from the surrounding environment which can attract attention and emphasize subject such as leading to observe blackboard-writing, teacher's move and expression, students' answer, experimental phenomenon and so on. Pushing: the scene is changed from small-scale view to large-scale view gradually in the shooting. For instance, from full shot or distant shot to close-up shot or close shot. It emphasizes the relationship between the subject and entire environment. For instance, it begins with the dedicated look from students, and then pulled slowly, and finally it ends with the close shot that the students are doing experiments attentively. Or it begins with the teacher, and then pulled slowly to the scene that the teacher is communicating with students, and finally it ends with the full shot that students are discussing fiercely. It shows the coherence and integrity of space with undoubted reality and reliability. Waving: The camera's position is fixed and view is unchanged, but the axis direction of camera is changed. Its shot is through rolling the camera in horizontal direction or vertical direction. You can use this shooting method to emphasize the atmosphere in class. Following: the shot closely follows the subject which makes the subject stay in the relative fixed position in the picture. It shows the dynamic expression of the subject. In the picture, the subject is not changed but the background and environment are changing. If we shoot when the teacher walk around the classroom, we must adjust the focal length to avoid the ambiguity of picture.

Choosing shooting site: Shooting site is also important, so we try to choose the high-light classroom and avoid shooting on cloudy day or rainy day. The size of classroom should be determined by the number of students. If it is too big, there will be more vacant space in the picture. The projection effect is determined by the distance between the platform and window and the sunlight and the light of the classroom. The location of mainframe is determined by the location of outlet and the surrounding noise. Therefore preparation work must be made well and fully and details and carelessness must be paid attention to. It can avoid reshooting and waste no time and energy.

\section{MAKE VIDEO MANUSCRIPT}

Video manuscript is the written form and contents of video teaching resource by characters and symbols. It is the basis of video teaching resource and recording and also determines the quality of video teaching resource. The manuscript is divided into written manuscript and shot manuscript. Teaching video resource is mostly lecture or teaching plan written manuscript which is done by teacher. Shot manuscript is the manuscript for shooting. It is first divided into numerous shots and then the content of every shot is written on the special form. The manuscript is separately finished by teacher and technician according to teaching aim.

\section{SHOOTING, COLLECTING, EDITING AND PUBLISHING OF VIDEO}

\subsection{Shooting}

After the early preparation is made, it moves into shooting stage. The most common way of shooting is using three sets of cameras: one for teacher, one for students and one for contents on the screen. The actual effect of shooting the contents on the screen is not good. If the light is low in the classroom, the effect of shooting the contents on the screen is good but the effect of shooting the teacher and students is not good. If the light is high in the classroom, the effect of shooting the contents on the screen is not good. Therefore we decide to use software for the contents on the screen such as Hyper-Cam. The form of the file is AVI and it is easy to be introduced to be cut. This method can reduce one set of camera and produce good effect, which is very suitable for school that is short of hands and equipment. In the classroom, firstly we should determine the location of cameras. The main camera for shooting the teacher should be located at the back of the classroom. The camera for shooting students should be located on the left or right side in the front of the classroom and avoid being shot in the main camera. The cameras should be fixed well by tripod and connected with power and audio cable. Then the white balances of cameras are adjusted by white paper so that the image tones of two are the same. We should install the software for shooting screen in the teacher's computer and adjust the resolution, frame rate and save path. The staffs present should turn off all the voice resources which may influence shooting such as cell phones. We must adjust the effect and volume of voice according to the normal class voice before shooting. We can begin to shoot after everything is checked. The main camera follows the teacher's activity in the shooting. The main camera begins and ends with full shot to show the classroom environment, and mainly uses mid-shot and close-up by push-and pull in between to show the teacher, blackboard-writing, screen and interaction between teacher and students. The camera for shooting students mostly uses close shot and lose-up to catch the situation that the students are listening attentively and they interact with each other by certain push-and pull. But we must avoid shooting the main camera. During the shooting, we must make gestures to the teacher before we change the tape. If any unexpected situation, reshoot or go no shooting is determined by the specific situation. Besides we should pay attention to some details: students should put irrelevant things such as cups in the drawer or on the ground to make sure the aesthetic picture. Students should listen attentively without any whispering or irrelevant action. Any student who answers any question should pause a few seconds to make sure the camera for students had time to catch it. It is good for later editing.

5.2 Collecting material

The priority of later editing by nonlinear editing is material collecting, that is, we put the material collected from the cameras in the hard disk. While we are doing this, we should watch the teaching video with the teacher 
through window. We should write down the timing location or make mark if we find something wrong and need correcting so that we can easily find the editing point for rough cutting to save time.

Because of using two cameras, we should integrate the materials of the two into one and pay attention to save complete communication between the teacher and students, for instance, the process of teacher's asking and correcting mistakes of students by the teacher. We must pay attention to the synchronization of voice and image. When we edit by EDIUS software, we import the material collected from the main camera to channel 1 and the material collected from the other camera to channel 2 . Then we lock channel where main camera material is in and adjust the locations of images on both channel again and again to edit the synchronized voice and image teaching video.

\subsection{Cutting and special effect}

The fine course teaching video should be as the same as the original teaching activity, thus it doesn't need much cutting and special effect. The main work is to cut the repeating or trivial contents. We can cut the unnecessary shot by connecting shot such as the contents at the same time: students' listening, manual operation and discussion in class.

There are 'dynamic to dynamic' and 'static to static' in connecting shots. We sometimes need connect 'dynamic' and 'static', for example, the teacher walks around when the student is answering a question. The shot should be changed from the teacher to the student. If we change directly, we will feel the visual sudden change. Then we can use gradual change between them which can play a buffering role to avoid the visual sudden change and increase sense of truth.

The shots connecting rule also includes reasonable transition of different shots. We may encounter this situation in the producing: The camera for shooting teacher is mid-shot and the other camera for shooting students is full shot. If we change directly, people will feel the sudden change of shot. But if we use slow cutting or gradual change effect, people will feel it goes naturally. Because the fine course teaching video is the direct reflection of teacher's manner and teaching activity, the application of special effect should be reasonable, appropriate, accurate and at good time to avoid no points of video, mess picture, loss of original teaching activity effect. If the teaching activity cannot be fully displayed such as conversation between teacher and students, we can use picture in picture skill to both show the teacher's manner in asking and student's emotion in answering, which gives a sense of communicating.

5.4 Output of files

We can preview it after the editing. If the teacher and relevant staffs are satisfied with it, the video can be output according to requirements. The form of the video can be flv first and then changed into swf. One advantage of swf is reduction of occupying the resource space. General video is bitmap while flash is vector. The definitions are the same despite the screen size. Swf is so popular that more than $99 \%$ of users can use it. Because of vector skill, it is small, fast and plays by flowing skill. It is playing while downloading, and if the speed is controlled well, you will not feel the downloading process. Flv is offered by software from the beginning of Flash MX 2004, but the new edition Flash 8 is better because it has an independent flv changing instrument Flash 8 Video Encoder. After we log in, the window is very simple. This tool is very convenient for changing video as flv with only a few steps.

To complete the video teaching resource well, preparation work must be made well and fully and details and carelessness must be paid attention to. It can avoid reshooting and waste no time and energy. Making full preparation is the key guarantee for developing high-quality teaching video resource.

[1] Shu Hui, Chen Jun. Talk about the making of fine course teaching video [J]. Chinese Medical Educational Technology.

[2]Wu Shunbi, Xu Lin. The problems and measures in online teaching video [J]. Chinese Medical Educational Technology.

[3] Huang Lixin. Analysis of the problems of teaching video in online course [J]. Electrical Educational Research.

[4] Chen Hongcai. Design and making of teaching video in online course [J]. Guangdong Radio and TV University Newspaper.

[5] Yang Bin, Zhong Huizhu. Analysis of video and voice making in teaching course cases [J]. Modern Educational Technology.

[6] Li Hongbo, Guoteng. Analysis for improving the quality in online course video. [J]. Chinese Adult Education.

[7] Chen Jun, Li Wenjian. Skills in making fine course teaching video. [J]. Scientific Information (Academic research).

[8] Jiang Wenbin. Design and making of fine course teaching video. [J]. Sichuan Professional and econdary College Newspaper. 